Research article

\title{
Vitis vinifera secondary metabolism as affected by sulfate depletion: Diagnosis through phenylpropanoid pathway genes and metabolites
}

\author{
Sílvia Tavares ${ }^{\mathrm{a}, \mathrm{b}}$, Damiano Vesentini ${ }^{\mathrm{b}}$, João Carlos Fernandes ${ }^{\mathrm{a}}$, Ricardo B. Ferreira ${ }^{\mathrm{a}, \mathrm{b}}$, Olga Laureano ${ }^{\mathrm{a}, \mathrm{c}}$, \\ Jorge M. Ricardo-Da-Silva ${ }^{\mathrm{a}, \mathrm{c}}$, Sara Amâncio ${ }^{\mathrm{a}, *}$ \\ ${ }^{a}$ CBAA/DRAT, Instituto Superior de Agronomia, UTL, 1349-017 Lisbon, Portugal \\ ${ }^{\mathrm{b}}$ ITQB, UNL, 2781-901 Oeiras, Portugal \\ ${ }^{c}$ Laboratório Ferreira Lapa (Sector de Enologia), Instituto Superior de Agronomia, UTL, 1349-017 Lisbon, Portugal
}

\section{A R T I C L E I N F O}

\section{Article history:}

Received 14 November 2012

Accepted 31 January 2013

Available online 27 February 2013

\section{Keywords:}

Anthocyanins

Chalcone synthase

Stilbenes

Stilbene synthase

Sulfur deficiency

Vitis vinifera

\begin{abstract}
A B S T R A C T
Grapevine (Vitis vinifera L.) is rich in phenylpropanoid compounds, namely flavonoids and stilbenes which, present in most tissues, are described as antioxidants and known to accumulate in response to biotic and abiotic stress. Grapevine is then a choice model for studying the interplay between the phenylpropanoid pathway and nutrient deficiency. Here we report the response to sulfur deficiency $(-S)$ of flavonoids and stilbenes biosynthetic pathways in chlorophyll tissues (plantlets) and cell culture. Anthocyanins and trans-resveratrol accumulated in plantlets and trans-resveratrol glucoside in cell cultures in response to sulfur deficiency, while a significant decrease in chlorophyll was observed in $-S$ plantlets. The up-regulation of chalcone synthase gene and the downstream flavonoid biosynthesis genes dihydroflavonol reductase and anthocyanidin synthase matched the accumulation of anthocyanins in $-S$ $V$. vinifera plantlets. The mRNA level of stilbene synthase gene(s) was correlated tightly with the increase in trans-resveratrol and trans-resveratrol glucoside levels, respectively in $-\mathrm{S}$ plantlets and cell cultures. As a whole, the present study unveil that $V$. vinifera under sulfur deficiency allocates resources to the phenylpropanoid pathway, probably consecutive to inhibition of protein synthesis, which can be advantageous to resist against oxidative stress symptoms evoked by $-\mathrm{S}$ conditions.
\end{abstract}

(c) 2013 Elsevier Masson SAS. All rights reserved.

\section{Introduction}

The phenylpropanoid biosynthetic pathway is widely spread in plant species conferring adaptive advantages to diverse ecosystems. Phenylpropanoids, phenyalanine-derived compounds, are phytochemicals not essential for plant survival, thus classified as plant secondary compounds. The deamination of L-phenylalanine by the action of phenylalanine ammonia-lyase (PAL) produces $t$-cinnamic acid, the precursor of all phenylpropanoids. Flavonoids, e.g. anthocyanins, and stilbenes are derived from $p$-coumaroyl-CoA, which undergoes cyclization and aromatization reactions, namely the sequential condensation of one p-coumaroyl-CoA with three malonyl-CoA molecules [1]. Chalcone, produced by chalcone

Abbreviations: ANS, anthocyanidin synthase gene; $C H S$, chalcone synthase gene; $D F R$, dihydroflavonol reductase gene; DW, dry weight; $F 3^{\prime}, 5^{\prime} H$, flavonoid $3^{\prime}, 5^{\prime}$-hydroxylase gene; GST, gluthathione $S$-transferase genes; STS, stilbene synthase; StSy, stilbene synthase gene; UFGT, UDP-glucose:flavonoid 3-O-glucosyltransferase gene;

$+\mathrm{S}$, sulfur sufficient conditions; $-\mathrm{S}$, sulfur deficient conditions.

* Corresponding author. Tel.: +351 213653418; fax: +351 213653383.

E-mail address: samport@isa.utl.pt (S. Amâncio). synthase (CHS) is the precursor of all the flavonoid compounds, while stilbene synthase (STS) is responsible for the production of stilbenes, such as resveratrol. The distinct nature of flavonoids (C15) and stilbenes (C14) lays merely in the decarboxilation step suffered by the second and since both enzymes use the same substrate [1], it has been proposed that STS evolved from CHS by gene duplication [2]. The latter is ubiquitous conversely to STS, which is restricted to a limited number of plant species, e.g. cranberries, blueberries, mulberries, peanuts, jackfruit, sorghum and pine [3].

Abiotic and biotic stress has been linked to the accumulation of polyphenols and to the increase in anthocyanin content [4,5]. Nutrient deficiency, such as nitrogen [6], phosphorus [7] and sulfur [8], can bring about the accumulation of anthocyanins and other polyphenols, although different classes of compounds seem to respond differently to environmental variation [9].

Vitis vinifera L. (grapevine) has a large variety of phenylpropanoid compounds, including polyphenols (flavonoids and stilbenes), which assume several roles during the plants life cycle. Flavonoids, including anthocyanins, are present in all $V$. vinifera tissues and have been described as powerful antioxidants, namely by protecting leaves or berries against UV photo-oxidative damage, 
functioning like seed dispersers and pollinator recruiters [4]. The stilbenes, resveratrol and derivatives, are classified as phytoalexins [10] due to their capacity to restrain fungal growth. In grapevine, the stilbene synthesis is induced by abiotic stress factors, such as aluminum [11], ozone exposure [12], UV light [13,14], mineral nitrogen depletion [15], soil lime [16], water stress [17], as well as methyl jasmonate (MeJA) [18].

Due to the powerful antioxidant properties grape and wine polyphenols hold a wide range of valuable effects in preventing heart diseases and cancer [19]. Also, the overall quality and characteristics of red grapes and wine taste are directly affected by the anthocyanin and polyphenols content and composition [20,21].

In grapevine, CHS is coded by a small family of three genes [22,23], unlike STS which belongs to a large gene family [22-25]. The downstream flavonoid biosynthetic pathway includes singlecopy genes like flavonoid 3-hydroxylase $\left(\mathrm{F}^{\prime} \mathrm{H}\right)$, dihydroflavonol reductase (DFR), anthocyanidin synthase (ANS or leucoanthocyanidin dioxygenase, LDOX), anthocyanidin reductase (ANR), and UDP-glucose:flavonoid 3-O-glucosyltransferase (UFGT), and a few large gene families, e.g. flavonoid $3^{\prime}, 5^{\prime}$-hydroxylase $\left(\mathrm{F}^{\prime}, 5^{\prime} \mathrm{H}\right)[24,25]$.

In grapevine berries, the anthocyanin content showed a strong correlation with the accumulation of UFGT mRNA [26], the first enzyme totally committed to anthocyanin biosynthesis, and its regulatory elements $V v M y b A[27,28]$, although anthocyanin composition was also influenced by the regulation of $F 3^{\prime} H, F 3^{\prime}, 5^{\prime} H$ and $O$-methyltransferase gene [20]. In fact, the methylation of anthocyanins by $O$-methyltransferase leads to color stabilization before their accumulation in the vacuole, which greatly affects anthocyanin properties in wine and its anti-oxidative power [20].

Gluthathione $S$-transferases (GSTs) were characterized in relation to the detoxification of xenobiotics [29] and to their ability for intracellular shuttling [30]. Several studies with maize mutants and functional complementation demonstrated that GSTs are involved in the accumulation of anthocyanins and proanthocyanidins [31], particularly in their transport to the vacuole [30]. Moreover the level of GST and UFGT transcripts showed similar patterns during grapevine ripening [20].

Considering the major investment of grapevine in the polyphenol pathway and the presence of stilbenes, it is considered a preferential model for studying the interplay between the synthesis of phenolic compounds and nutrient deficiency. Here we report for the first time the response of flavonoid and stilbene biosynthetic pathways to sulfur deficiency in heterotrophic grapevine leaves and isolated cells. For that purpose, we analyzed the accumulation of phenolic compounds in different sulfur conditions, with special attention to anthocyanins and resveratrol and derivatives. Finally, the crosstalk between gene expression for the main biosynthetic enzymes and the accumulation of the correspondent metabolites was examined under changing sulfur conditions.

\section{Results}

\subsection{Physiological responses to sulfur deficiency}

The measurement of physiological parameters is a valuable mean to assess the effect of imposed conditions on the functioning of biological experimental systems. Low sulfate $(-S)$ availability significantly reduced the growth of $V$. vinifera plantlets. The $-\mathrm{S}$ conditions affected severely total biomass and repressed plantlet branching and, consequently, leaf number. The branch and leaf number was respectively $75 \%$ and $80 \%$ higher in $+S$ plantlets at the 2nd week (Table 1 ), a tendency that was confirmed after 4 weeks growth, when $+S$ plantlets showed in average 2.45 shoots, unlike the majority of $-S$ plantlets which maintained but the initial branch, and 12 against 5leaves, when $+\mathrm{S}$ and $-\mathrm{S}$ plantlets are compared (Table 1).

As a symptom of normal physiological shape, the total chlorophyll content of $+\mathrm{S}$ shoots did not change during the 4 weeks of multiplication treatment (Table 1 ) while the $-S$ conditions significantly affected the total chlorophyll content of the shoots. At the 4 th week, $-S$ shoots showed the lowest chlorophyll content resulting in visible symptoms of chlorosis. The chlorophyll $a / b$ ratio was similar in both conditions studied with a slight tendency for decreasing during the second half of the growth period.

Comparing the biomass of $+S$ to $-S$ cell cultures along the growth cycle, after a latency period of three days in both conditions, increasing values were obtained. After five days in culture cells in $+\mathrm{S}$ medium showed a statistically higher fresh weight than $-\mathrm{S}$ cells ( 4.8 vs $4 \mathrm{~g}$ ) and such a tendency was even more clear at day 7 in culture, when the FW of $-\mathrm{S}$ cells was the same as at day $0,3 \mathrm{~g}$, while $+S$ cells attained the highest value, $5.8 \mathrm{~g}$ (Table 1 ). $V$. vinifera cells growing in $-\mathrm{S}$ during a 7 days cycle showed increasing brown color as compared to cells growing in $+\mathrm{S}$ conditions which maintained a white-yellow color (Supplementary Figure S1).

\subsection{Total phenolic compounds}

An increase in the content of total phenolic compounds was observed in response to sulfur deficiency in both experimental systems. Total phenolic content was higher in -S plantlets after two weeks, although not statistically significant and even though declining towards the 4th week in both conditions, a significantly higher value was obtained in $-\mathrm{S}$ conditions (Table 2). In an FW basis $+S$ cells presented lower phenolic content than control plantlets which increased under $-\mathrm{S}$ conditions (Table 2 ).

In Table 2 we show that the precipitated fraction corresponds to the main input to the total phenolic content in both experimental systems and conditions, while soluble monophenols and o-diphenols represent a smaller fraction of total phenols, contributing in lesser extent to the response to $-\mathrm{S}$ conditions.

Table 1

The effect of sulfate availability on physiological parameters of Vitis vinifera cv Touriga Nacional plantlets and biomass of cell culture.

\begin{tabular}{|c|c|c|c|c|c|c|c|c|c|c|c|c|}
\hline \multirow{2}{*}{$\begin{array}{l}\text { Treatment } \\
\text { Plantlets }\end{array}$} & \multicolumn{6}{|l|}{$+\mathrm{S}$} & \multicolumn{6}{|l|}{$-\mathrm{S}$} \\
\hline & 0 & & $2 \mathrm{wk}$ & & $4 \mathrm{wk}$ & & 0 & & $2 \mathrm{wk}$ & & $4 \mathrm{wk}$ & \\
\hline Fresh weight (g) & $0.11 \mathrm{c}$ & & $0.18 \mathrm{~b}$ & & $0.25 a$ & & $0.11 \mathrm{c}$ & & $0.09 c$ & & $0.09 c$ & \\
\hline Branch number & $1 \mathrm{c}$ & & $1.75 b$ & & $2.45 a$ & & $1 c$ & & $1.03 \mathrm{c}$ & & $1.16 \mathrm{c}$ & \\
\hline Leaf number & $3 c$ & & $7.00 \mathrm{~b}$ & & $12.31 \mathrm{a}$ & & $3 c$ & & $3.85 c$ & & $5.17 \mathrm{~b}$ & \\
\hline Total chl $\left(\mathrm{mg} \mathrm{cm}^{-2}\right)$ & $0.02 \mathrm{a}$ & & $0.018 \mathrm{a}$ & & $0.018 \mathrm{a}$ & & $0.02 \mathrm{a}$ & & $0.015 b$ & & $0.011 \mathrm{c}$ & \\
\hline Chla/Chlb & 3 & & 3.09 & & 2.58 & & 3 & & 2.99 & & 2.78 & \\
\hline Cell culture & 0 & $1 d$ & $3 d$ & $4 d$ & $5 d$ & $7 d$ & 0 & $1 d$ & $3 d$ & $4 d$ & $5 d$ & $7 d$ \\
\hline Fresh weight (g) & 2.9 & 2.2 & 3.1 & 3.8 & 4.8 & $5.8 \mathrm{a}$ & 2.8 & 2.5 & 3.4 & 4.1 & 4 & $3 b$ \\
\hline
\end{tabular}

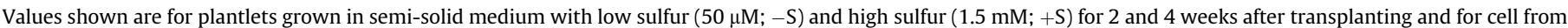
liquid culture grown for 7 days in the same sulfur conditions.

Each value is the mean of $3-15$ replicates of two independent experiments. Different letters correspond to significant differences ( $p<0.05$ ). 
Table 2

The effect of sulfur on total phenolic content and phenolic compounds differentially precipitated with formaldehyde in Vitis vinifera cv Touriga Nacional plantlets and cell culture.

\begin{tabular}{|c|c|c|c|c|c|c|}
\hline \multirow[b]{2}{*}{ Treatment } & \multicolumn{2}{|c|}{$\begin{array}{l}\text { Phenols ( } \mu \mathrm{g}(+)- \\
\left.\text { catechin } \mathrm{mg}^{-1} \mathrm{DW}\right)\end{array}$} & \multicolumn{2}{|c|}{$\begin{array}{l}\text { Precipitated with } \\
\text { formaldehyde }\end{array}$} & \multicolumn{2}{|c|}{$\begin{array}{l}\text { Non-precipitated } \\
\text { with formaldehyde }\end{array}$} \\
\hline & $+\mathrm{S}$ & $-\mathrm{S}$ & $+\mathrm{S}$ & $-\mathrm{S}$ & $+\mathrm{S}$ & $-S$ \\
\hline \multicolumn{7}{|l|}{ Plantlets } \\
\hline $2 \mathrm{wk}$ & 66.9a & $85.4 a$ & $55.2 b$ & $71.8 \mathrm{a}$ & $11.7 \mathrm{c}$ & $13.6 \mathrm{~b}$ \\
\hline $4 \mathrm{wk}$ & $41.2 \mathrm{~b}$ & $70.3 a$ & $34.8 \mathrm{c}$ & $54.3 b$ & $14.1 \mathrm{~b}$ & $16.7 a$ \\
\hline \multicolumn{7}{|l|}{ Cells } \\
\hline $1 \mathrm{~d}$ & $9.3 b$ & $9.5 b$ & $5.8 \mathrm{~b}$ & $6.1 b$ & $3.5 b$ & $3.4 \mathrm{~b}$ \\
\hline $4 d$ & $9.3 b$ & $13.4 a$ & $6.3 b$ & $9.1 a$ & $3.0 \mathrm{~b}$ & $4.4 a$ \\
\hline $7 d$ & $9.5 b$ & 11.9a & $5.7 \mathrm{~b}$ & $8.5 a$ & 3.8ab & $3.4 \mathrm{~b}$ \\
\hline
\end{tabular}

Values shown are for plantlets grown in semi-solid medium with low sulfur $(50 \mu \mathrm{M} ;-\mathrm{S})$ and high sulfur $(1.5 \mathrm{mM} ;+\mathrm{S})$ for 2 and 4 weeks after transplanting and for cells from liquid culture grown for 7 days in the same sulfur conditions.

Each value is the mean of 3-4 replicates. Different letters correspond to significant differences $(p<0.05)$. DW, dry weight.

\subsection{Anthocyanin accumulation in V. vinifera plantlets}

Sulfate deficiency caused an increase in anthocyanin accumulation in $V$. vinifera plantlets. Two weeks $-S$ treatment led to a moderate and not statistically different raise in anthocyanin. The highest value was obtained in plantlets subjected to sulfate deficiency for four weeks $(p<0.01)$. After two and four weeks the control plantlets maintained the same anthocyanin content (Fig. 1).

Cell cultures grown under light exposition did not show any accumulation of anthocyanins in both sulfate conditions, at least as measured by the applied photometric technique.

\subsection{Stilbene production}

In methanol extracts obtained from $V$. vinifera plantlets growing in $+S$ or $-S$ conditions and analyzed by HPLC, we could detect and quantify the stilbene compounds trans-resveratrol, trans-resveratrol glucoside and the oxidized form, $\varepsilon$-viniferin (Fig. 2A). Trans-resveratrol was the predominant stilbene measured in both treatments, with ca $0.50 \mu \mathrm{g} \mathrm{mg}^{-1} \mathrm{DW}$ in $+\mathrm{S}$ plantlets, raised significantly in $-\mathrm{S}$ conditions to 1.29 and $0.87 \mu \mathrm{g} \mathrm{mg}^{-1} \mathrm{DW}$, respectively at the 2 nd and 4 th week, 1.7- to 2.5-fold increase (Fig. 2A). Therefore in plantlets, trans-resveratrol showed the greatest response to sulfate deficiency; $\varepsilon$-viniferin increased moderately under $-\mathrm{S}$ conditions (although

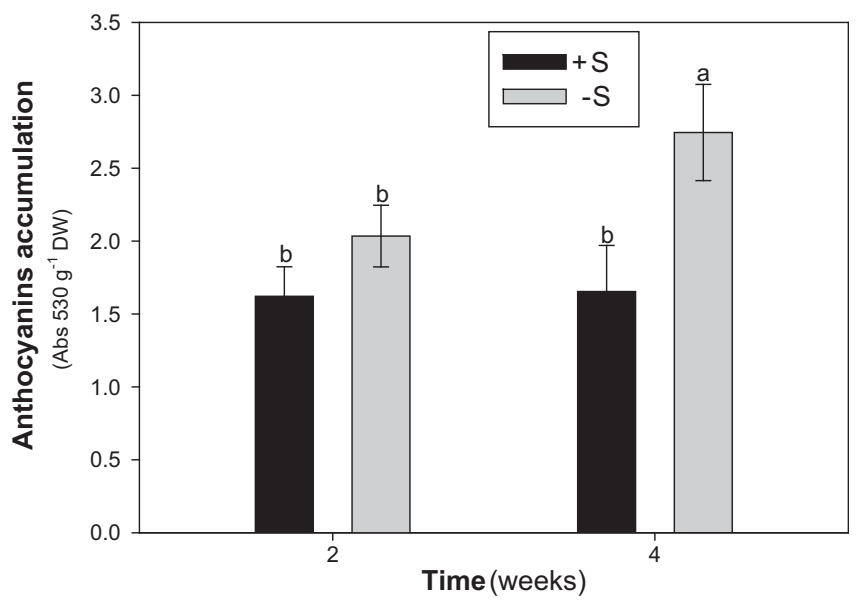

Fig. 1. Effect of sulfate on accumulation of anthocyanins in Vitis vinifera cv Touriga Nacional plantlets grown in low sulfur $(50 \mu \mathrm{M} ;-\mathrm{S})$ and high sulfur $(1.5 \mathrm{mM} ;+\mathrm{S})$ semisolid medium for 2 and 4 weeks. Error bars represent $\pm S D ; n=4$. Columns topped by the same letter are not significantly different $(p<0.05)$ as determined by LSD. DW, dry weight.
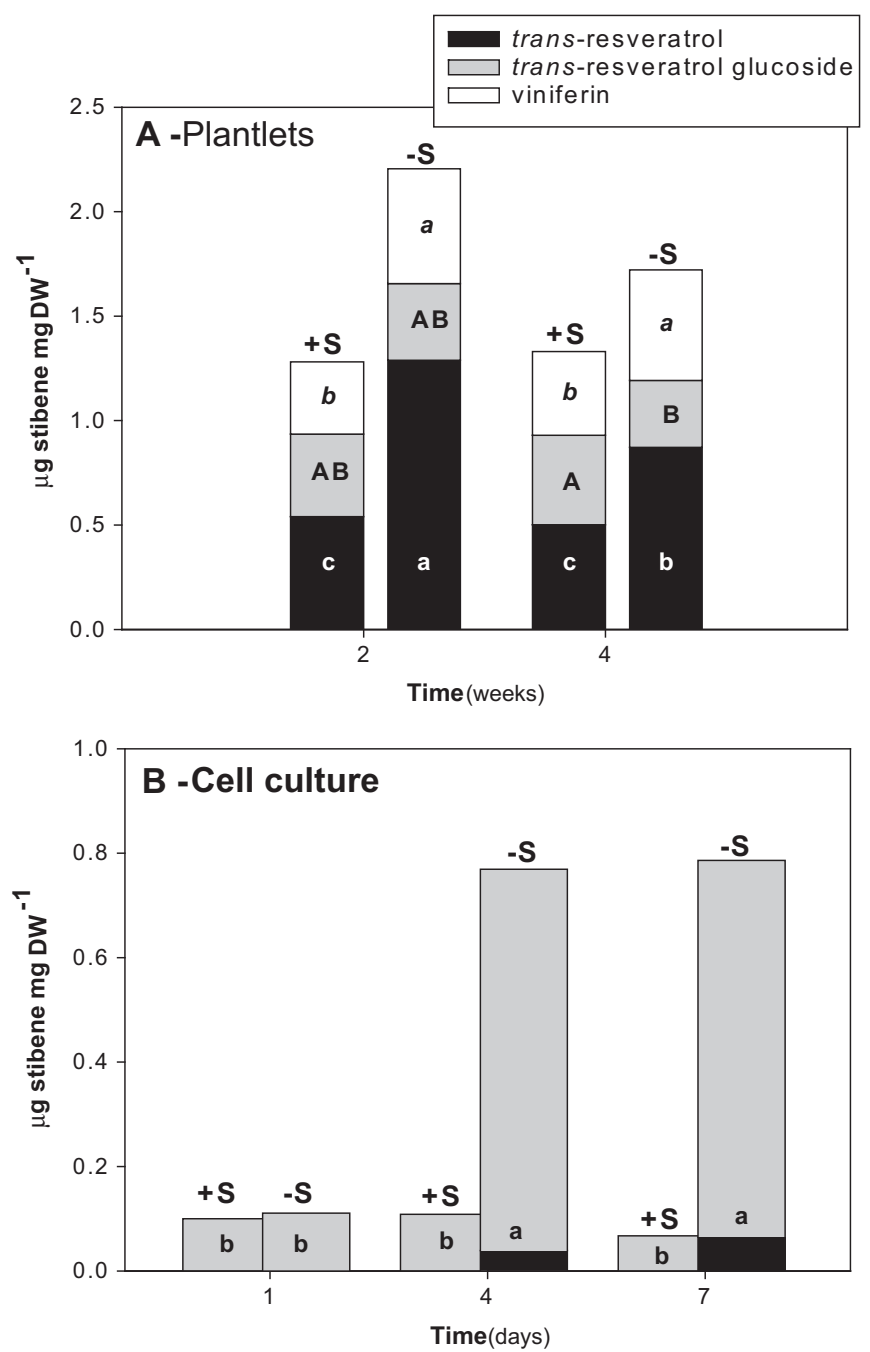

Fig. 2. Effect of sulfate on the accumulation of the stilbenes, trans-resveratrol, transresveratrol glucoside and $\varepsilon$-viniferin in Vitis vinifera cv Touriga Nacional plantlets (A) and cell cultures (B). Samples were taken from $V$. vinifera plantlets grown for 2 and 4 weeks and cell cultures grown for 1,4 and 7 days in full sulfate $(1.5 \mathrm{mM},+\mathrm{S})$ or sulfate deficient $(50 \mu \mathrm{M} ;-S)$ semi-solid medium and liquid medium, respectively Columns with the same letter are not significantly different $(p<0.05$ in plantlets $(A)$ and $p<0.01$ in cell culture (B)) as determined by LSD; $n=6$. Note the change in scale of $y$ axis and $x$-axis between A and B. DW, dry weight.

significantly, $p<0.05$ ) and the content in trans-resveratrol glucoside was almost constant under the two sulfate conditions (Fig. 2A).

The HPLC analysis of extracts from cell cultures allowed the detection of trans-resveratrol glucoside. The non-glucoside transresveratrol could be detected in small amounts, 0.04 and $0.06 \mu \mathrm{g} \mathrm{mg}^{-1} \mathrm{DW}$ after 4 and 7 days in $-S$ conditions, respectively. $\varepsilon$-viniferin was absent in $+S$ and $-S$ cells, or below the limits of our HPLC analysis (Fig. 2B). In $+\mathrm{S}$ conditions, the amount of transresveratrol glucoside was maintained constant along the growth cycle and similar to the content in $-\mathrm{S}$ cells collected at day $1(+\mathrm{S}$, $\left.0.10 ;-S, 0.11 \mu \mathrm{g} \mathrm{mg}^{-1} \mathrm{DW}\right)$. However after four days in $-\mathrm{S}$, the measured trans-resveratrol glucoside revealed a 7-fold boost, which was maintained at the 7 th day in $-\mathrm{S}$ cells (Fig. 2B).

2.5. The expression of most genes involved in the phenypropanoid pathway is up-regulated by sulfur deficiency

Chalcone synthase and stilbene synthase are the enzymes that define the first branching point of the phenypropanoid biosynthetic 
pathway. The primers designed for CHS gene amplified only one isoform (Table 3), although the primers design for StSy amplified three distinct isoforms (Table 3). The transcription level of chalcone synthase (CHS) gene and stilbene synthase (StSy) genes increased, respectively, 8.0 and 6.1 times in plantlets of $V$. vinifera under $-S$ conditions after 2 and 4 weeks growth (Fig. 3A). Other genes of the phenylpropanoid pathway also responded to the nutrient deficiency, such as dihydroflavonol reductase (DFR) and anthocyanidin synthase (ANS), the first moderately, by increasing 3.8-fold, and the second at the same level of CHS and StSy after 2 weeks in -S conditions (Fig. 3A). Flavonoid $3^{\prime}, 5^{\prime}$-hydroxylase $\left(F 3^{\prime}, 5^{\prime} H\right)$ and UDPglucose:flavonoid 3-O-glucosyltransferase (UFGT) did not seem to respond to the $-\mathrm{S}$ conditions.

Gluthathione $S$-transferase (GST) addressed due to its role in the transport and accumulation of phenylpropanoid compounds into the vacuole, was up-regulated by 6.5 times in $V$. vinifera plantlets under sulfur limitation (Fig. 3A).

In cell culture CHS and StSy mRNA reacted strongly to sulfate deficiency but in opposite directions (Fig. 3B). After one day in $-\mathrm{S}$ medium, the transcription level of $C H S$ did not change and that of StSy was slightly up-regulated (4-fold increase). However after four days the tendency for a down-regulation of $C H S$ and up-regulation of StSy transcripts was accentuated and after seven days in $-\mathrm{S}$ conditions, CHS reached ca a 60 -fold repression and StSy a 100 -fold increase (Fig. 3B). Several genes acting downstream to CHS were also down-regulated in $-\mathrm{S}$ cells, such as $A N S$, or did not respond to the deficiency conditions in cell culture, e.g. DFR (Fig. 3B). Although we could not quantify anthocyanins we could detect mRNA of the genes addressed to the biosynthesis of these flavonoids, such as UFGT.

\subsection{The expression of a laccase-like gene}

Considering the role of laccases on the oxidation of phenolic compounds, the transcription level of a laccase-like gene was also measured. In $-S$ plantlets its mRNA did not change (Fig. 3A). Conversely, in cell culture the transcript of the same laccase-like gene was dramatically up-regulated even before the response observed in StSy (Fig. 3B). In fact, after 4 days in - S, a 70 -fold increase was observed in laccase-like gene expression, a trend that was maintained till the end of the cell growth cycle, when its upregulation was similar to the one observed for StSy (Fig. 3B).

\section{Discussion}

Using grapevine cell systems we showed previously that sulfate deficiency up-regulates sulfate influx and the expression of the transcripts of sulfate transporters [32]. Here we describe the effect of sulfate deficiency on flavonoid and stilbene contents and on the expression of genes for the enzymes of the correspondent biosynthetic pathway in two experimental models, the grapevine cell system and leaf tissue of in vitro plantlets.

\subsection{Slow down of growth of $V$. vinifera plantlets and cell cultures under sulfur deficiency}

Sulfur deficiency significantly reduced the overall growth of $V$. vinifera plantlets, especially the number of new shoots (branching) confirming previous results obtained with an equivalent experimental system [33]. The cell culture biomass was also affected by sulfur deficiency an effect explained by the moderate accumulation of sulfate in grapevine cells, so rapidly exhausted when they are transferred to $-\mathrm{S}$ conditions [32]. A reduction in biomass was also observed in Arabidopsis thaliana seedlings under sulfur starvation conditions $[8,34]$. The general growth retardation matches the repression in metabolic activity evident by the significant decrease in chlorophyll content in $-\mathrm{S} V$. vinifera plantlets. Several species, such as Spinacia oleracea [35], Brassica napus [36], Beta vulgaris [37] and A. thaliana [8,34] also responded to sulfur deficiency by lowering the chlorophyll content, an effect assumed as a loss of photosynthetic capacity [38]. The metabolic profiling of A. thaliana under sulfur deficiency showed that the concentration in chlorophyll pathway metabolites was the second most affected after that involving sulfur assimilation metabolites [34].

\subsection{High accumulation of phenolic compounds under sulfur deficiency: moderate impact on anthocyanin content and major response at stilbene level}

Different authors, combining several observations revised by Manetas [39] put forward the hypothesis that any retardation of plant growth can lead to surplus of carbon-nitrogen skeletons, which are not assimilated into proteins and remain available for the synthesis of secondary metabolism compounds, namely phenylpropanoids, considering that proteins and phenylpropanoids compete for the same precursor, the amino acid phenylalanine. Phenolic compounds are then secondary carbon-rich metabolites, which accumulate under nutrient deficiency conditions [40], such as low nitrogen [9,41] and sulfur deficiency in A. thaliana [34] and grapevine (the present research). Flavonoids, flavonoid-derived (e.g. condensed tannins) and stilbenes were the main phenolics rising after sulfur limitation. Anthocyanins and stilbenes were then elected for a closer attention since their synthesis is downstream the first branching point of the phenylpropanoid pathway.

Table 3

Primer sequences used for quantitative real-time polymerase chain reaction.

\begin{tabular}{|c|c|c|c|c|}
\hline Gene symbol & Gene ID (V0 Genoscope, NCBI) ${ }^{\mathrm{a}}$ & Forward primer $\left(5^{\prime}-3^{\prime}\right)$ & Reverse primer $\left(5^{\prime}-3^{\prime}\right)$ & $\begin{array}{l}\text { Amplicon } \\
\text { length (bp) }\end{array}$ \\
\hline CHS & GSVIVT00032968001 & CCGACGAAGTTCACACTGATTCAAG & GATAGTCAGCCTGGTAGACACAGTT & 143 \\
\hline$F 3^{\prime}, 5^{\prime} H$ & GSVIVT00022298001 & CATCAAGCGTAATCGAGTGGTCTCT & CCTTGCATATGGCTTGTAGGTATGG & 156 \\
\hline DFR & GSVIVT00009743001 & TCATCACTATCATACCGACTCTTGT & CCTGCCGTATAATTGAATAATGAGC & 123 \\
\hline ANS & GSVIVT00019892001 & CAACAATGCTAGTGGACAGCTTGAG & TGGAACGTAGTCGCTTGGTGTCTTA & 112 \\
\hline UFGT & GSVIVT00024419001 & CCTCATGCAGTCTTCTCCTTCTTCA & CACCGTCGGAGATATCATAGGACTT & 112 \\
\hline GST & GSVIVT00014973001 & GCGGACTACATAGACAAGAAGCTC & TTCACCACCGAAGTAAGGCTTCTC & 150 \\
\hline \multirow[t]{3}{*}{ StSy } & GSVIVT00010590001 & GACCACTGTGTCTACCAGTCTGATT & GCAGTGATAATCTCTTGGCGTATGT & 218 \\
\hline & GSVIVT00010557001 & & & \\
\hline & GSVIVT00010554001 & & & \\
\hline Laccase & GSVIVT00012329001 & AGAAGTATCCAGCACGTTTACGAGT & CСССTGTTCTGGTGTCAATAAAGTA & 108 \\
\hline
\end{tabular}

Primers designed using Clone manager 6 software.

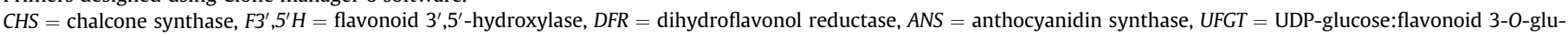
cosyltransferase, GST = gluthathione $S$-transferases, StSy = stilbene synthase, laccase = laccase-type.

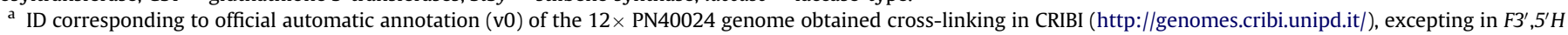
gene which was obtained from the $8 \times$ PN40024 genome annotation. 

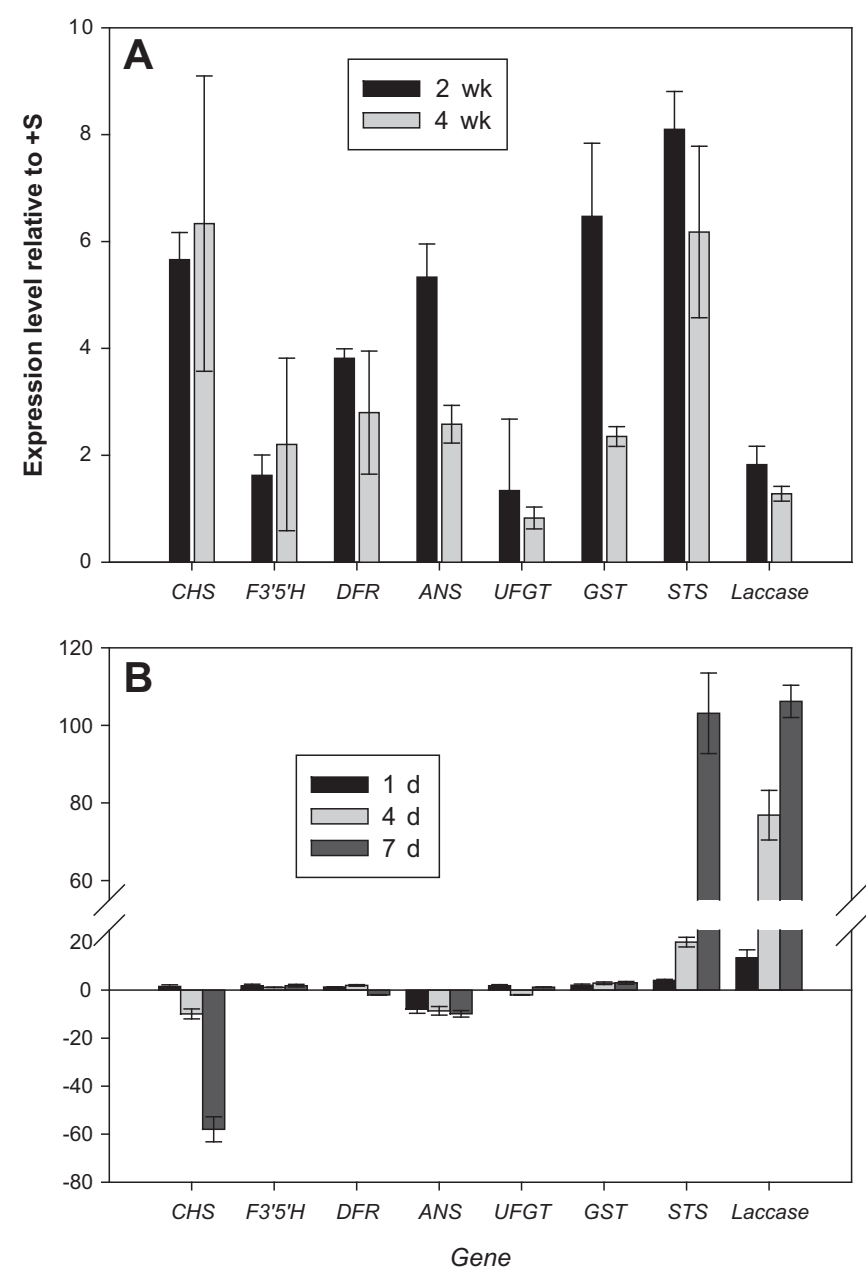

Fig. 3. Expression of flavonoid and stilbene biosynthetic pathway genes altered by sulfate deficiency $(50 \mu \mathrm{M},-S)$ in plantlets of Vitis vinifera cv Touriga Nacional grown for 2 and 4 weeks in semi-solid medium (A) and the same genes and laccase in cell suspensions grown in $-\mathrm{S}(50 \mu \mathrm{M})$ or $+\mathrm{S}(1.5 \mathrm{mM})$ medium, for 1,4 and 7 days (B). CHS, chalcone synthase; $F 3^{\prime}, 5^{\prime} H$, flavonoid 3',5'-hydroxylase; $D F R$, dihydroflavonol reductase; ANS, anthocyanidin synthase; UFGT, UDP-glucose:flavonoid 3-O-glucosyltransferase; GST, gluthathione S-transferase; StSy, stilbene synthase, laccase, laccase. RNA levels were normalized against the expression of Act2 RNA as described in Methods. Raw Ct values for Act2 expression in 2 weeks V. vinifera plantlets were 23.6 and 23.0 and in 4 weeks plantlets 20.6 and 21.1, in $-S$ and $+S$, respectively. Error bars represent $\pm \mathrm{SD} ; n=3$. The raw $\mathrm{Ct}$ values for Act2 expression in $V$. vinifera cells for day 1 were 18.9 and 19.3, for day 4 were 19.1 and 19.7, and for day 7, 19.8 and 19.2, under $-S$ and $+\mathrm{S}$ conditions, respectively. Error bars represent $\pm \mathrm{SD} ; n=3$.

Anthocyanin accumulation is considered a common response to stress conditions [5], including the deficiency in nitrogen in grapevine cells [6], phosphorus in A. thaliana and tomato [42,7] and sulfur in A. thaliana [34] and grapevine plantlets (the present study). Chalker-Scott [43] suggests that anthocyanins have different protective effects: absorbing high radiation wavelengths, scavenging reactive oxygen species and acting as osmotic adjusters. The former can be of especial importance in sulfur depletion conditions, considering that the decline in chlorophyll and the even stronger decrease in sulfolipids, associated with the impairment in light absorbance and photosynthetic capacity as observed in A. thaliana $[8,34]$, points to metabolic conditions where even low light intensities can be sensed as light stress.

Belhadj et al. [44] working with a grapevine cell system, describe the accumulation of anthocyanin induced by jasmonates. Interestingly, in the same direction, are the results of a microarray analysis of A. thaliana seedlings grown under sulfur depletion which showed an increase in the level of transcripts implicated in auxin and jasmonic acid biosynthesis $[8,38]$. It is not to exclude that the symptoms observed in grapevine plantlets, namely branching inhibition, result from impairment in the biosynthesis of growth regulators [33].

Conversely to flavonoids, which are ubiquitous in plants, stilbenes are specific to certain plant families including Vitaceae. It is worth noting that the two experimental systems applied in the present study showed marked differences in accumulated stilbenes, with trans-resveratrol glucoside predominant in cell cultures and trans-resveratrol in plantlets. Trans-resveratrol glucoside can be considered a storage form of trans-resveratrol, protected from enzymatic oxidation, which could give raise to toxic forms, as is the case of viniferins [45], additionally it increases the half-life of trans-resveratrol released by hydrolysis of trans-resveratrol glucoside. Differences in the stilbene content between plantlets and cell culture can also result from the cell conditions in terms of endogenous $\beta$-glucosidase expression and oxidation patterns.

Previous reports show that, in grapevine, stilbenes rapidly accumulate in response to different stress conditions, namely aluminum [11], fungal infection [10,46], ozone exposure [12], jasmonates and cyclodextrin [44,47], UV radiation [14] and water stress [17]. Research conducted with plants transformed with the gene for stilbene synthase permitted an insight into possible biological functions of stilbene compounds in plant cells revised by Delaunois et al. [3]. The antioxidant properties of several transgenic plants increased substantially when transformed with StSy, e.g. transgenic tomato plants transformed with StSy under the constitutive promoter 35SCaMV increased their antioxidant capacity through higher ascorbate/glutathione content [48]. Recent work by Fornara et al. [49] localizes stilbene synthase (STS), to the cell wall of berry skin and Pan et al. [14] observed an increased in STS activity in primary and secondary cell walls of UV-treated cells, consistent with an optimized function as protective compounds.

\subsection{The interplay between flavonoid and stilbene pathway genes under sulfur deficiency}

Stilbene and flavonoid syntheses share the same precursor and have a common origin in the general phenylpropanoid metabolism, with a branch point at stilbene synthase (STS) and chalcone synthase (CHS) level. In our $V$. vinifera plantlet system the transcript levels for CHS and StSy matched well the increase in anthocyanins and stilbenes under $-S$ conditions. During grapevine berry development the accumulation of anthocyanins was strongly correlated with the transcription of UFGT and $F 3^{\prime} 5^{\prime} H$ [20], conversely to our sulfate deficiency conditions. However in other nutrient deficient conditions, namely nitrogen [50] and phosphorus [51] in the model plant A. thaliana, the accumulation of anthocyanins paralleled with the up-regulation of anthocyanin pathway genes CHS, DFR and ANS. It is then plausible that the accumulation of anthocyanins observed in general nutrient deficiency is under transcriptional control at the level of the former genes. The MYB transcription factors could be good candidates to mediate the transcriptional control, since MYB75 and MYB90 (or PAP1 and PAP2) associated with the regulation of the flavonoid biosynthesis pathway were up-regulated under sulfur deficiency as depicted in microarray analysis [8], but also under nitrogen and phosphorus deficiency [52,53]. The two MYBs mentioned were characterized as globally enhancing the expression of the target genes CHS, DFR and GST [52], which, interestingly, also respond to sulfur deficiency in $V$. vinifera plantlets.

In $V$. vinifera plantlets glutathione S-tranferase (GST) transcripts increase in response to $-S$ conditions. GST proteins have been shown to bind flavonoids in vitro [30] and mediate the conjugation between anthocyanins and gluthathione in maize [29] leading to the protective storage of these pigments into plant vacuoles, 
although in grapevine cell cultures GST transcripts level did not change, probably due to the different nature of the phenolic compounds accumulated in response to the nutrient deficiency.

Stilbenes, as anthocyanins, are known to increase under various stress conditions, grapevine plantlets and cell culture in $-\mathrm{S}$ conditions both accumulated stilbenes, although with marked differences in the nature of the stilbenes, well correlated with the increase in StSy transcription suggesting also transcription control at level of StSy genes in cell culture. In Cabernet Sauvignon berries under water stress [17], the glycosylated form also accumulated and was correlated with the StSy transcript, since the resveratrol-Oglycosyltransferase gene expression was maintained constant. The StSy transcript control seems to be the regulatory step in the production of trans-resveratrol and derivatives compounds.

An earlier event to the increase in StSy transcript(s) expression in $-S$ conditions is the expression boost of a grapevine sequence with high homology to plant laccases. Together with the brown color depicted by cell culture after 4-7 days under sulfur deficiency suggested us that the polyphenolic compounds, especially stilbenes, could be the target for laccase oxidation, which are polyphenol oxidases using $o$ - and $p$-diphenols as substrates [54]. A direct link between oxidative polymerization of flavonoids and laccase activity was obtained with the Arabidopsis tt10 mutant with an uncolored seed coat phenotype [55]. Also, in the interaction of grapevine with Botrytis cinerea, the role of laccase activity in the detoxification of resveratrol by oxidation has been previously considered [56]. Taking into consideration the function and localization of laccases in cell walls (together with STS), we can speculate that in grapevine cell cultures tested in the present study, the high amounts of resveratrol ( $p$-diphenols) were prone to laccase oxidation resulting in the phenotype observed in cell culture.

Although the accumulation of anthocyanins was not detected in cell cultures, all genes related to the flavonoid pathway were present in the mRNA pool in full and deficient conditions, with CHS and ANS transcripts progressively repressed under $-S$ conditions, a striking and distinct response when compared with the same conditions in grapevine plantlets. Fischer et al. [57] demonstrated for the first time the interaction between the two metabolic pathways by transforming tobacco seedlings with an StSy gene: resveratrol accumulated while the flowers changed color and male sterility was observed. The authors speculate that the presence of StSy created a competition for metabolites common to the two branches of phenylpropanoid biosynthesis pathway, a feature also suggested in $V$. vinifera different tissues and developmental stages [23]. In fact, Jeandet et al. [58] observed, during berry maturation, an accumulation of anthocyanins and a decrease in resveratrol production, together with a repression of StSy gene.

Grapevine plantlets clearly invest in both phenylpropanoid pathways, to generate flavonoids and stilbenes, while cell cultures only produce stilbenes (Fig. 4). Plantlets have green tissues, with photosynthetic capacity, what seems to agree with a photoprotective role of anthocyanins, while stilbenes can impair oxidative stress in both systems. In cell cultures, the great up-regulation of StSy, and eventually of its enzymatic product STS, which can compete for the same substrate as CHS, may lead to repressing the transcription of CHS and other genes downstream the same pathway (Fig. 4), proposing a sort of interaction between both branch phenylpropanoid pathways.

In $V$. vinifera plantlets, sulfur deficiency was responsible for the coordination and up-regulation of CHS, DFR, ANS and GST expression, apparently in correlation with the increase of anthocyanin content and probable accumulation in the vacuole. Regarding the stilbene pathway, StSy mRNA level increased in both experimental systems, as well as trans-resveratrol and viniferin in plantlets and trans-resveratrol glucoside in cell cultures (Fig. 4).

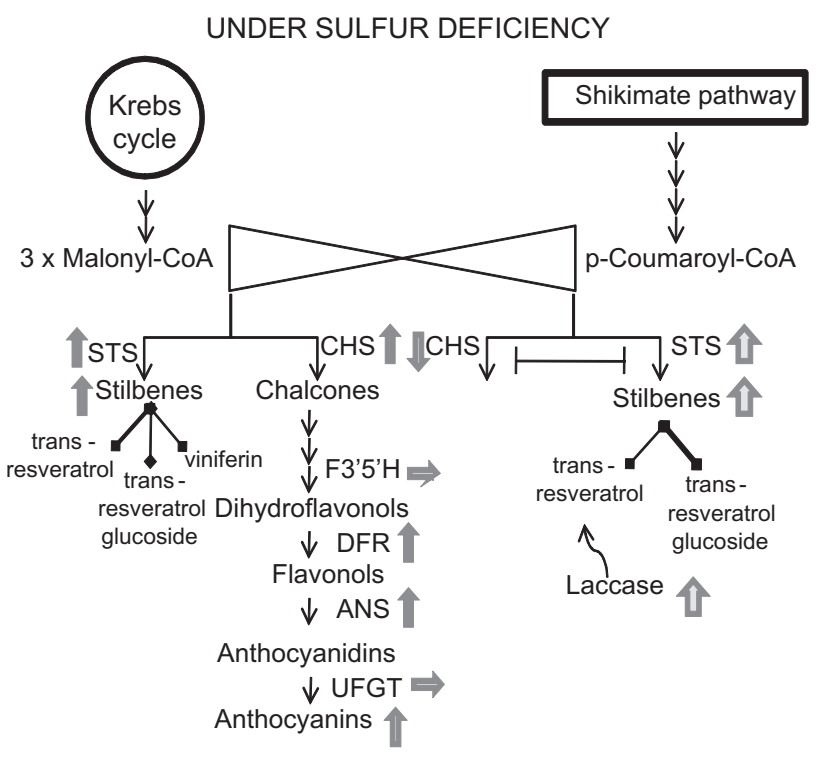

Photosynthetic tissue

Non-photosynthetic tissue

Fig. 4. Schematic overview of the two initial branches of the phenylpropanoid pathway, for anthocyanin and stilbene biosynthesis, highlighting the main results obtained in plantlets (photosynthetic tissue) and cell cultures (non-photosynthetic cells) of Vitis vinifera cv Touriga Nacional under sulfur deficiency. Abbreviations: CHS, chalcone synthase; $F 3^{\prime}, 5^{\prime} H$, flavonoid 3',5'-hydroxylase; DFR, dihydroflavonol reductase; ANS, anthocyanidin synthase; UFGT, UDP-glucose:flavonoid 3-O-glucosyltransferase; StSy, stilbene synthase. Legend: $\Uparrow$ - increase; $\sqrt{-}$ - decrease and $\Rightarrow-$ no changes in the level of gene expression and metabolite accumulation.

Taking the whole results into account we can conclude that the response to sulfur deficiency of $V$. vinifera photosynthetic and nonphotosynthetic tissues and cells point out to distinct strategies in phenylpropanoid pathway and metabolite accumulation (Fig. 4).

\section{Materials and methods}

\subsection{Plant materials, culture media and experimental conditions}

In vitro shoots (plantlets) of $V$. vinifera $\mathrm{L}$. cV. Touriga Nacional were obtained by multiplication and sub-cultured every 4 weeks into Murashige and Skoog (MS; [59]) medium supplemented with $30 \mathrm{~g} \mathrm{~L}^{-1}$ sucrose, $0.5 \mu \mathrm{M}$ 1-naphthaleneacetic acid (NAA) and $5.0 \mu \mathrm{M}$ benzylaminopurine (BAP) [60], pH 5.8, $2 \mathrm{~g} \mathrm{~L}^{-1}$ gelrite. Light was from fluorescent lamps at a photon flux density (PFD) of $45 \pm 10 \mu \mathrm{mol} \mathrm{m}^{-2} \mathrm{~s}^{-1}$ and a photoperiod of $16 \mathrm{~L}-8 \mathrm{D}$.

Cell suspensions of $V$. vinifera $\mathrm{L}$. cv. Touriga Nacional were obtained by adapting to liquid culture callus material maintained in the dark at $25^{\circ} \mathrm{C}$, as described in Jackson et al. [61]. About $4 \mathrm{~g}$ callus tissue were dispersed in $50 \mathrm{~mL}$ of liquid medium containing MS basal salts supplemented with $2.5 \mu \mathrm{M}$ 2,4-dichlorophenoxy-acetic acid (2,4-D), $5 \mathrm{~g} \mathrm{~L}^{-1}$ polyvinylpyrrolidone-40T, $20 \mathrm{~g} \mathrm{~L}^{-1}$ sucrose and $1 \mu \mathrm{M}$ kinetin. The cultures growing in $250 \mathrm{~mL}$ flasks on a rotary shaker at $100 \mathrm{rpm}$, under the same light conditions described above, at $25^{\circ} \mathrm{C}$ were sub-cultured weekly by diluting $25 \mathrm{~mL}$ culture into $25 \mathrm{~mL}$ of new medium [32].

Two sulfate treatments were applied full sulfate $(1.5 \mathrm{mM},+\mathrm{S})$ and sulfated efficient ( $50 \mu \mathrm{M},-\mathrm{S})$, after four weekly cycles in $+\mathrm{S}$ conditions. Commercial MS (Duchefa Biochemie, Haarlem, NL) (1.5 mM sulfate) was used for $+S$ experiments while a modified MS medium where sulfates were substituted for chlorides was considered $-\mathrm{S}[62,8]$. 
Samples from cell cultures were collected at days 1, 4 and 7 after the onset of sulfur stress and from plantlets after 2 and 4 weeks growth in $-\mathrm{S}$ medium. All samples were frozen in liquid nitrogen, lyophilized in $50 \mathrm{~mL}$ plastic test tubes and pulverized under liquid nitrogen.

\subsection{Physiological parameters}

FW was registered at days $0,1,3,4,5$ and 7 of cell culture from at least three flasks per treatment of two independent experiments. At the second and fourth week of plantlets growth, FW and the number of new branches and of leaves were recorded.

Chlorophyll was extracted according to the method developed by Hiscox and Israelstam [63]. Four leaf discs (total area $113 \mathrm{~mm}^{2}$ ) were incubated in $3 \mathrm{~mL}$ DMSO at $65^{\circ} \mathrm{C}$ for $30 \mathrm{~min}$, and absorbance was measured at 645 and $663 \mathrm{~nm}$.

The Arnon's equations [64] was used to calculate the chlorophyll concentration: Chla $\left(\mathrm{g} \mathrm{L}^{-1}\right)=0.0127 \mathrm{~A}_{663}-0.00269 \mathrm{~A}_{645}$; Chlb $\left(\mathrm{g} \mathrm{L}^{-1}\right)=0.0229 \mathrm{~A}_{645}-0.00468 \mathrm{~A}_{663}$; tot Chl $\left(\mathrm{g} \mathrm{L}^{-1}\right)=0.0202$ $\mathrm{A}_{645}+0.00802 \mathrm{~A}_{663}$. The $\mathrm{Chl}$ concentration was then converted to

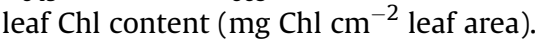

\subsection{Total phenolic content}

Soluble phenolic compounds were isolated from cells and plantlets by extraction into methanol acidified with $0.1 \%(\mathrm{v} / \mathrm{v}) \mathrm{HCl}$. Ground tissue (40-60 mg) was added of $3 \mathrm{~mL}$ extraction solution, gently shaken for 2-h at room temperature. The methanol extract was diluted 10:1 with water and absorbance was assayed at $280 \mathrm{~nm}$, with (+)-catechin as standard, in a Shimadzu UV-265 spectrophotometer (Japan).

The reaction between formaldehyde and m-diphenols or p-diphenols under acidic conditions, often named Stiasny reaction, produces a precipitate following the formation of methylene bridges between the A-rings of two or more molecules [65]. Thus, the Stiasny reaction allowed a first separation within the total phenolic compounds. After the determination of total phenolic content in the plant extract as described above, $2.5 \mathrm{~mL}$ of $20 \%$ (v/v) $\mathrm{HCl}$ and $1.75 \mathrm{~mL}$ formaldehyde were added to $2.5 \mathrm{~mL}$ of plant extract. The reaction was incubated overnight at room temperature; the un-precipitated phenols were estimated at $280 \mathrm{~nm}$. The precipitate contained flavonoids, proanthocyanidins and stilbenes, while the monophenol and $o$-diphenol fraction was maintained in solution.

\subsection{Anthocyanin quantification}

Samples of plantlets grown for 2 and 4 weeks and of cell cultures at days 1,4 and 7 , in $+S$ and $-\mathrm{S}$ conditions were used for anthocyanin quantification based on the procedure developed by Bariola et al. [66]. Ground tissue was gently shaken in $1.5 \mathrm{~mL}$ of $1 \%(\mathrm{v} / \mathrm{v})$ $\mathrm{HCl} /$ methanol for $2 \mathrm{~h}$ at room temperature. Subsequently, $1.2 \mathrm{~mL}$ chloroform was added to the mixture and vortexed vigorously, prior to the addition of $3 \mathrm{~mL}$ of deionized water. The mixture was vortexed again and centrifuged for $3 \mathrm{~min}$ at $6000 \mathrm{~g}$. The supernatant was removed and the absorbance of a $1 \mathrm{~mL}$ aliquot was measured at $530 \mathrm{~nm}$ and $657 \mathrm{~nm}$ in a Shimadzu UV-265 spectrophotometer (Japan). The latter wavelength was used to compensate for the absorbance of chlorophyll. The anthocyanin content was obtained by the difference between $A_{530}$ and $A_{657}$. Values were normalized to the dry weight of each sample.

\subsection{HPLC analysis of stilbene compounds}

The reversed-phase HPLC analytical separation of stilbenes was performed according to the method of Pussa et al. [67] and Martin et al. [68], with the modifications specified below, using a Waters 1525 binary pump linked to a Waters 2996 photodiode array detector (PDA). The HPLC equipment was coupled to a Waters Symmetry C18 column with a guard column filled with the same type of sorbent in a gradient mode of $0.1 \%(\mathrm{v} / \mathrm{v})$ formic acid (solvent A) and acetonitrile (solvent B) at a flow rate of $0.5 \mathrm{~mL} \mathrm{m^{-1 }}$ at $35^{\circ} \mathrm{C}$. Elution started with a linear gradient of $\mathrm{B}$ from 10 to $30 \%$ for $20 \mathrm{~min}$ and then to $90 \%$ for $60 \mathrm{~min}$. The final elution was isocratic with $100 \%$ B for 10 min to wash the column. The sample injection volume was $50 \mu \mathrm{L}$. The PDA detector was set at an interval of $220-600 \mathrm{~nm}$. The optical density of the eluate was monitored at the maximum absorbance wavelength for each peak $\left(\lambda_{\max }\right), 305 \mathrm{~nm}$ for trans-resveratrol, $320 \mathrm{~nm}$ for transresveratrol glucoside and $323 \mathrm{~nm}$ for $\varepsilon$-viniferin. Quantification of individual peaks was achieved by comparison to the sample internal standard pterostilbene. Identification of the chromatographic peaks was performed by comparison to known standards: trans-resveratrol, trans-resveratrol glucoside and pterostilbene obtained from Sigma-Aldrich. Putative identification of $\varepsilon$-viniferin was by comparison with the results of Pussa et al. [67] and Martin et al. [68].

\subsection{RNA isolation and reverse transcriptase-PCR}

RNA from $V$. vinifera plantlets was extracted according to the method described by Reid et al. [69]. RNA from cell culture was isolated using the RNeasy ${ }^{\circledR}$ Plant Mini Kit (Qiagen, Hilden, Germany) following the manufacturer's instructions. RNA samples were treated with RNase free DNaseI (Qiagen, Hilden, Germany) according to the manufacturer protocol and quantified using absorption of UV light at $260 \mathrm{~nm}$. Reverse transcription was carried out using superscript III RNase H-reverse transcriptase priming with oligo-d(T) ${ }_{20}$ (Invitrogen, Carlsbad, CA) according to the manufacturer's recommendations. Complementary DNA (cDNA) was synthesized from $1 \mu \mathrm{g}$ total RNA after DNaseI treatment.

\subsection{Quantitative real-time $R T-P C R(q P C R)$}

Primers to the genes under analysis designed using Clone Manager 6 (Scientific and Educational Software, Durham, USA) are indicated in Table 3. Quantitative real-time PCRs were performed in $20 \mu \mathrm{L}$ of reaction mixture composed of cDNA, $0.5 \mu \mathrm{M}$ of primers and master mix iQ SYBR Green Supermix (Bio-Rad, Hercules, CA) using an iQ5 Real-Time PCR (Bio-Rad, Hercules, CA). Reactions conditions for thermal cycling were: $95^{\circ} \mathrm{C}, 3 \mathrm{~min}$; then 40 cycles at $95^{\circ} \mathrm{C} 15 \mathrm{~s}$, $60{ }^{\circ} \mathrm{C} 30 \mathrm{~s}, 72{ }^{\circ} \mathrm{C} 20 \mathrm{~s}$. Each reaction was performed in triplicate and the specificity of amplification products was confirmed by the melting curve and gel electrophoresis analysis. Data were analyzed with the iQ5 optical system software (Bio-Rad, Hercules, CA) and exported into an MS Excel workbook (Microsoft Inc.) for further analysis. Transcript levels were normalized to Act2 transcript levels, a housekeeping gene found to be expressed at constant level in the conditions tested [70]. The method described by Livak and Schmittgen [71] was applied to compare the transcript levels in $-S$ and $+\mathrm{S}$ conditions.

\subsection{Statistical analysis}

For each parameter, $-S$ treatment and control $(+S)$ were performed at least twice in triplicate. The results were statistically evaluated by variance analysis (ANOVA) using MS Excel workbook (Microsoft Inc.) software. Data are presented \pm standard deviation (SD). Two-way ANOVA was conducted with least significance difference (LSD) statistic when sulfate level or time of growth had significant effects. Each experiment consisted of two sulfate 
conditions and two or three time points for plantlets and cell culture, respectively. The sulfate and time effects were tested at $p<0.05$ and $p<0.01$, respectively.

\section{Acknowledgements}

The authors thank Graziela Rodrigues for technical assistance and Mafalda Moita for cell cultures. This work was funded by Fundação para a Ciência e Tecnologia (FCT), Portugal (project POCTI/AGG/46607/2002). S. Tavares and D. Vesentini received PhD (SFRH/BD/18904/2004) and postdoctoral (SFRH/BPD/26564/2006) grants, respectively, from FCT.

\section{Appendix A. Supplementary data}

Supplementary data related to this article can be found at http://dx.doi.org/10.1016/j.plaphy.2013.01.022.

\section{References}

[1] J.P. Noel, M.B. Austin, E.K. Bomati, Structure-function relationships in plant phenylpropanoid biosynthesis, Curr. Opin. Plant Biol. 8 (2005) 249-253.

[2] S. Tropf, T. Lanz, S.A. Rensing, J. Schroder, G. Schroder, Evidence that stilbene synthases have developed from chalcone synthases several times in the course of evolution, J. Mol. Evol. 38 (1994) 610-618.

[3] B. Delaunois, S. Cordelier, A. Conreux, C. Clement, P. Jeandet, Molecular engineering of resveratrol in plants, Plant Biotechnol. J. 7 (2009) 2-12.

[4] B. Winkel-Shirley, Biosynthesis of flavonoids and effects of stress, Curr. Opin. Plant Biol. 5 (2002) 218-223.

[5] L. Chalker-Scott, J.D. Scott, Elevated ultraviolet-B radiation induces crossprotection to cold in leaves of Rhododendron under field conditions, Photochem. Photobiol. 79 (2004) 199-204.

[6] C.B. Do, F. Cormier, Effects of low nitrate and high sugar concentrations on anthocyanin content and composition of grape (Vitis vinifera $\mathrm{L}$ ) cell suspension, Plant Cell. Rep. 9 (1991) 500-504

[7] A.J. Stewart, W. Chapman, G.I. Jenkins, I. Graham, T. Martin, A. Crozier, The effect of nitrogen and phosphorus deficiency on flavonol accumulation in plant tissues, Plant Cell. Environ. 24 (2001) 1189-1197.

[8] V. Nikiforova, J. Freitag, S. Kempa, M. Adamik, H. Hesse, R. Hoefgen, Transcriptome analysis of sulfur depletion in Arabidopsis thaliana: interlacing of biosynthetic pathways provides response specificity, Plant J. 33 (2003) 633-650.

[9] R.M. Muzika, Terpenes and phenolics in response to nitrogen fertilization: a test of the carbon/nutrient balance hypothesis, Chemoecology 4 (1993) 3-7.

[10] M. Adrian, P. Jeandet, J. Veneau, L.A. Weston, R. Bessis, Biological activity of resveratrol, a stilbenic compound from grapevines, against Botrytis cinerea, the causal agent for gray mold, J. Chem. Ecol. 23 (1997) 1689-1702.

[11] M. Adrian, P. Jeandet, R. Bessis, J.M. Joubert, Induction of phytoalexin (resveratrol) synthesis in grapevine leaves treated with aluminum chloride $\left(\mathrm{AlCl}_{3}\right)$, J. Agric. Food Chem. 44 (1996) 1979-1981.

[12] R. Schubert, R. Fischer, R. Hain, P.H. Schreier, G. Bahnweg, D. Ernst H. Sandermann, An ozone-responsive region of the grapevine resveratrol synthase promoter differs from the basal pathogen-responsive sequence, Plant Mol. Biol. 34 (1997) 417-426.

[13] M. Adrian, P. Jeandet, A.C. Douillet-Breuil, L. Tesson, R. Bessis, Stilbene content of mature Vitis vinifera berries in response to UV-C elicitation, J. Agric. Food Chem. 48 (2000) 6103-6105.

[14] Q.H. Pan, L. Wang, J.M. Li, Amounts and subcellular localization of stilbene synthase in response of grape berries to UV irradiation, Plant Sci. 176 (2009) 360-366.

[15] L. Bavaresco, S. Pezzutto, A. Ragga, F. Ferrari, M. Trevisan, Effect of nitrogen supply on trans-resveratrol concentration in berries of Vitis vinifera L. cV Cabernet Sauvignon, Vitis 40 (2001) 229-230.

[16] L. Bavaresco, S. Civardi, S. Pezzutto, S. Vezzulli, F. Ferrari, Grape production, technological parameters, and stilbenic compounds as affected by limeinduced chlorosis, Vitis 44 (2005) 63-65.

[17] L.G. DeLuc, A. Decendit, Y. Papastamoulis, J.M. Merillon, J.C. Cushman, G.R. Cramer, Water deficit increases stilbene metabolism in Cabernet Sauvignon berries, J. Agric. Food Chem. 59 (2011) 289-297.

[18] S. Vezzulli, P. Battilani, L. Bavaresco, Stilbene-synthase gene expression after Aspergillus carbonarius infection in grapes, Am. J. Enol. Vitic. 58 (2007) 530-533.

[19] M. Jang, L. Cai, G.O. Udeani, K.V. Slowing, C.F. Thomas, C.W. Beecher, H.H. Fong N.R. Farnsworth, A.D. Kinghorn, R.G. Mehta, R.C. Moon, J.M. Pezzuto, Cance chemopreventive activity of resveratrol, a natural product derived from grapes, Science 275 (1997) 218-220.

[20] S.D. Castellarin, G. Di Gaspero, Transcriptional control of anthocyanin biosynthetic genes in extreme phenotypes for berry pigmentation of naturally occurring grapevines, BMC Plant Biol. 7 (2007) 46, http://dx.doi.org/10.1186/ 1471-2229-7-46.

[21] F. Cosme, J.M. Ricardo-Da-Silva, O. Laureano, Tannin profiles of Vitis vinifera L. cv. red grapes growing in Lisbon and from their monovarietal wines, Food Chem. 112 (2009) 197-204.

[22] C. Parage, R. Tavares, S. Rety, R. Baltenweck-Guyot, A. Poutaraud, L. Renault, D. Heintz, R. Lugan, G. Marais, S. Aubourg, P. Hugueney, Structural, functional, and evolutionary analysis of the unusually large stilbene synthase gene family in grapevine, Plant Physiol. 160 (2012) 1407-1419.

[23] A. Vannozzi, I.B. Dry, M. Fasoli, S. Zenoni, M. Lucchin, Genome-wide analysis of the grapevine stilbene synthase multigenic family: genomic organization and expression profiles upon biotic and abiotic stresses, BMC Plant Biol. 12 (2012) 130, http://dx.doi.org/10.1186/1471-2229-12-130.

[24] F. Sparvoli, C. Martin, A. Scienza, G. Gavazzi, C. Tonelli, Cloning and molecular analysis of structural genes involved in flavonoid and stilbene biosynthesis in grape (Vitis vinifera L.), Plant Mol. Biol. 24 (1994) 743-755.

[25] R. Velasco, A. Zharkikh, M. Troggio, D.A. Cartwright, A. Cestaro, D. Pruss, M. Pindo, L.M. Fitzgerald, S. Vezzulli, J. Reid, et al., A high quality draft consensus sequence of the genome of a heterozygous grapevine variety, PLoS ONE 2 (2007) e1326, http://dx.doi.org/10.1371/journal.pone.0001326.

[26] P.K. Boss, C. Davies, S.P. Robinson, Analysis of the expression of anthocyanin pathway genes in developing Vitis vinifera L. cv Shiraz grape berries and the implications for pathway regulation, Plant Physiol. 111 (1996) 1059-1066.

[27] C.M. Ford, P.K. Boss, P.B. Hoj, Cloning and characterization of Vitis vinifera UDP-glucose:flavonoid 3-O-glucosyltransferase, a homologue of the enzyme encoded by the maize Bronze-1 locus that may primarily serve to glucosylate anthocyanidins in vivo, J. Biol. Chem. 273 (1998) 9224-9233.

[28] S. Kobayashi, M. Ishimaru, K. Hiraoka, C. Honda, Myb-related genes of the Kyoho grape (Vitis labruscana) regulate anthocyanin biosynthesis, Planta 215 (2002) 924-933.

[29] K.A. Marrs, M.R. Alfenito, A.M. Lloyd, V. Walbot, A glutathione S-transferase involved in vacuolar transfer encoded by the maize gene Bronze-2, Nature 375 (1995) 397-400.

[30] S. Conn, C. Curtin, A. Bezier, C. Franco, W. Zhang, Purification, molecular cloning, and characterization of glutathione S-transferases (GSTs) from pigmented Vitis vinifera L. cell suspension cultures as putative anthocyanin transport proteins, J. Exp. Bot. 59 (2008) 3621-3634.

[31] S. Kitamura, N. Shikazono, A. Tanaka, TRANSPARENT TESTA 19 is involved in the accumulation of both anthocyanins and proanthocyanidins in Arabidopsis, Plant J. 37 (2004) 104-114.

[32] S. Tavares, C. Sousa, L.C. Carvalho, S. Amâncio, Derepressed sulfate transporters are strongly and rapidly repressed after sulfate addition to sulfurdepleted Vitis cells, Int. J. Plant Sci. 169 (2008) 987-997.

[33] J. Fernandes, S. Tavares, S. Amâncio, Identification and expression of cytokinin signaling and meristem identity genes in sulfur deficient grapevine (Vitis vinifera L.), Plant Signal. Behav. 4 (2009) 1128-1135.

[34] V. Nikiforova, J. Kopka, V. Tolstikov, O. Fiehn, L. Hopkins, M.J. Hawkesford, H. Hesse, R. Hoefgen, Systems rebalancing of metabolism in response to sulfur deprivation, as revealed by metabolome analysis of Arabidopsis plants, Plant Physiol. 138 (2005) 304-318.

[35] A.G.S. Warrilow, M.J. Hawkesford, Separation, subcellular location and influence of sulphur nutrition on isoforms of cysteine synthase in spinach, J. Exp. Bot. 49 (1998) 1625-1636.

[36] M.M. Blake-Kalff, K.R. Harrison, M.J. Hawkesford, F.J. Zhao, S.P. McGrath Distribution of sulfur within oilseed rape leaves in response to sulfur deficiency during vegetative growth, Plant Physiol. 118 (1998) 1337-1344.

[37] S.G. Thomas, P.E. Bilsborrow, TJ. Hocking. J. Bennett, Effect of sulphur deficiency on the growth and metabolism of sugar beet (Beta vulgaris cv Druid), J. Agric. Food Chem. 80 (2000) 2057-2062.

[38] M.Y. Hirai, T. Fujiwara, M. Awazuhara, T. Kimura, M. Noji, K. Saito, Global expression profiling of sulfur-starved Arabidopsis by DNA macroarray reveals the role of O-acetyl-l-serine as a general regulator of gene expression in response to sulfur nutrition, Plant J. 33 (2003) 651-663.

[39] Y. Manetas, Why some leaves are anthocyanic and why most anthocyanic leaves are red? Flora 201 (2006) 163-177.

[40] J.P. Bryant, F.S. Chapin, D.R. Klein, Carbon nutrient balance of boreal plants in relation to vertebrate herbivory, Oikos 40 (1983) 357-368.

[41] C. Fritz, N. Palacios-Rojas, R. Feil, M. Stitt, Regulation of secondary metabolism by the carbon-nitrogen status in tobacco: nitrate inhibits large sectors of phenylpropanoid metabolism, Plant J. 46 (2006) 533-548.

[42] M.C. Trull, M.J. Guiltinan, J.P. Lynch, J. Deikman, The responses of wild-type and ABA mutant Arabidopsis thaliana plants to phosphorus starvation, Plant Cell. Environ. 20 (1997) 85-92.

[43] L. Chalker-Scott, Environmental significance of anthocyanins in plant stress responses, Photochem. Photobiol. 70 (1999) 1-9.

[44] A. Belhadj, N. Telef, C. Saigne, S. Cluzet, F. Barrieu, S. Hamdi, J.M. Merillon, Effect of methyl jasmonate in combination with carbohydrates on gene expression of PR proteins, stilbene and anthocyanin accumulation in grapevine cell cultures, Plant Physiol. Biochem. 46 (2008) 493-499.

[45] R. Pezet, K. Gindro, O. Viret, J.L. Spring, Glycosylation and oxidative dimerization of resveratrol are respectively associated to sensitivity and resistance of grapevine cultivars to downy mildew, Physiol. Mol. Plant Pathol. 65 (2004) $297-303$. 
[46] L. Bavaresco, S. Vezzulli, P. Battilani, P. Giorni, A. Pietri, T. Bertuzzi, Effect of ochratoxin A-producing Aspergilli on stilbenic phytoalexin synthesis in grapes, J. Agric. Food Chem. 51 (2003) 6151-6157.

[47] D. Lijavetzky, L. Almagro, S. Belchi-Navarro, J.M. Martinez-Zapater, R. Bru, M.A. Pedreno, Synergistic effect of methyljasmonate and cyclodextrin on stilbene biosynthesis pathway gene expression and resveratrol production in Monastrell grapevine cell cultures, BMC Res. Notes 1 (2008) 132, http:// dx.doi.org/10.1186/1756-0500-1-132.

[48] G. Giovinazzo, L. d'Amico, A. Paradiso, R. Bollini, F. Sparvoli, L. DeGara, Antioxidant metabolite profiles in tomato fruit constitutively expressing the grapevine stilbene synthase gene, Plant Biotechnol. J. 3 (2005) 57-69.

[49] V. Fornara, E. Onelli, F. Sparvoli, M. Rossoni, R. Aina, G. Marino, S. Citterio, Localization of stilbene synthase in Vitis vinifera L. during berry development, Protoplasma 233 (2008) 83-93.

[50] W.R. Scheible, R. Morcuende, T. Czechowski, C. Fritz, D. Osuna, N. PalaciosRojas, D. Schindelasch, O. Thimm, M.K. Udvardi, M. Stitt, Genome-wide reprogramming of primary and secondary metabolism, protein synthesis, cellular growth processes, and the regulatory infrastructure of Arabidopsis in response to nitrogen, Plant Physiol. 136 (2004) 2483-2499.

[51] R. Muller, M. Morant, H. Jarmer, L. Nilsson, T.H. Nielsen, Genome-wide analysis of the Arabidopsis leaf transcriptome reveals interaction of phosphate and sugar metabolism, Plant Physiol. 143 (2007) 156-171.

[52] R. Stracke, H. Ishihara, G. Huep, A Barsch, F. Mehrtens, K Niehaus, B. Weisshaar, Differential regulation of closely related R2R3-MYB transcription factors controls flavonol accumulation in different parts of the Arabidopsis thaliana seedling, Plant J. 50 (2007) 660-677.

[53] C. Lillo, U.S. Lea, P. Ruoff, Nutrient depletion as a key factor for manipulating gene expression and product formation in different branches of the flavonoid pathway, Plant Cell. Environ. 31 (2008) 587-601.

[54] S. Guyot, J. Vercauteren, V. Cheynier, Structural determination of colourless and yellow dimers resulting from $(+)$-catechin coupling catalysed by grape polyphenoloxidase, Phytochemistry 42 (1996) 1279-1288.

[55] L. Pourcel, J.M. Routaboul, L. Kerhoas, M. Caboche, L. Lepiniec, I. Debeaujon, TRANSPARENT TESTA10 encodes a laccase-like enzyme involved in oxidative polymerization of flavonoids in Arabidopsis seed coat, Plant Cell 17 (2005) 2966-2980.

[56] A.C. Breuil, P. Jeandet, M. Adrian, F. Chopin, N. Pirio, P. Meunier, R. Bessis Characterization of a pterostilbene dehydrodimer produced by laccase of Botrytis cinerea, Phytopathology 89 (1999) 298-302.

[57] R. Fischer, I. Budde, R. Hain, Stilbene synthase gene expression causes changes in flower colour and male sterility in tobacco, Plant J. 11 (1997) 489-498.
[58] P. Jeandet, R. Bessis, B. Gautheron, The production of resveratrol (3,5,4'-trihydroxystilbene) by grape berries in different developmental stages, Am. J. Enol. Vitic. 42 (1991) 41-46.

[59] T. Murashige, F. Skoog, A revised medium for rapid growth and bioassays with tobacco tissue cultures, Physiol. Plant 15 (1962) 473.

[60] C. Neves, M.C. Sa, S. Amâncio, Histochemical detection of $\mathrm{H}_{2} \mathrm{O}_{2}$ by tissue printing as a precocious marker of rhizogenesis in grapevine, Plant Physiol. Biochem. 36 (1998) 817-824.

[61] P.A. Jackson, C.I. Galinha, C.S. Pereira, A. Fortunato, N.C. Soares, S.B. Amâncio, C.P. Pinto Ricardo, Rapid deposition of extensin during the elicitation of grapevine callus cultures is specifically catalyzed by a 40 -kilodalton peroxidase, Plant Physiol. 127 (2001) 1065-1076.

[62] H. Takahashi, A Watanabe-Takahashi, F.W. Smith, M. Blake-Kalf, M.J. Hawkesford, K. Saito, The roles of three functional sulfate transporters involved in uptake and translocation of sulfate in Arabidopsis thaliana, Plant J 23 (2000) 171-182.

[63] J.D. Hiscox, G.F. Israelstam, A method for the extraction of chlorophyll from leaf tissue without maceration, Can. J. Bot. 57 (1979) 1332-1334.

64] D.I. Arnon, Copper enzymes in isolated chloroplasts. Polyphenoloxidase in Beta vulgaris, Plant Physiol. 24 (1949) 1-15.

[65] A. Scalbert, Quantitative methods for the estimation of tannins in plant tissues, in: P.E.L.R.W. Hemingway (Ed.), Plant Polyphenols: Synthesis, Properties, Significance, Plenum Press, New York, New York, 1992, pp. 259-280.

[66] P.A. Bariola, G.C. MacIntosh, P.J. Green, Regulation of S-like ribonuclease levels in Arabidopsis. Antisense inhibition of RNS1 or RNS2 elevates anthocyanin accumulation, Plant Physiol. 119 (1999) 331-342.

[67] T. Pussa, J. Floren, P. Kuldkepp, A. Raal, Survey of grapevine Vitis vinifera stem polyphenols by liquid chromatography-diode array detection-tandem mass spectrometry, J. Agric. Food Chem. 54 (2006) 7488-7494.

68] N. Martin, D. Vesentini, C. Rego, S. Monteiro, H. Oliveira, R.B. Ferreira, Phaeomoniella chlamydospora infection induces changes in phenolic compounds content in Vitis vinifera, Phytopathol. Mediterr. 48 (2009) 101-116.

[69] K.E. Reid, N. Olsson, J. Schlosser, F. Peng, S.T. Lund, An optimized grapevine RNA isolation procedure and statistical determination of reference genes for real-time RT-PCR during berry development, BMC Plant Biol. 6 (2006) 27, http://dx.doi.org/10.1186/1471-2229-6-27.

[70] Y.Q An, J.M. McDowell, S.R. Huang, E.C. McKinney, S. Chambliss, R.B. Meagher, Strong, constitutive expression of the Arabidopsis ACT2/ACT8 actin subclass in vegetative tissues, Plant J. 10 (1996) 107-121.

[71] K.J. Livak, T.D. Schmittgen, Analysis of relative gene expression data using realtime quantitative PCR and the $2^{-\Delta \Delta C T}$ method, Methods 25 (2001) 402-408. 